\title{
Efektivitas Model Pembelajaran Tutor Sebaya untuk Meningkatkan Kemampuan Membaca Al-Qur'an Siswa pada Mata Pelajaran Al-Qur'an Hadits di Madrasah Ibtidaiyah Al-Hidayah
}

\author{
Apriyana $^{1^{*}}$, Amir Rusdi ${ }^{2}$, Dian Erlina ${ }^{3}$ \\ ${ }^{1 *}$ Madrasah Ibtidaiyah Al-Hidayah, Palembang, Indonesia \\ apriyana2018@gmail.com \\ ${ }^{2}$ Universitas Islam Negeri Raden Fatah, Palembang, Indonesia \\ amirrusdi_uin@radenfatah.ac.id \\ ${ }^{3}$ Universitas Islam Negeri Raden Fatah, Palembang, Indonesia \\ dianerlina_uin@radenfatah.ac.id
}

\begin{abstract}
The purpose of this study is to look at the implementation and effectiveness of peer tutoring learning models in improving the ability to read Al-Quran students on the Al-Quran Hadith subjects in madrasas ibtidaiyah Al-Hidayah Palembang. This type of research is field research using quantitative research approaches and the design used is quasi-experimental. The instrument of data collection was carried out by interviewing, observing, and documenting as well as analyzing the data using the $T$ test. From the results of the research the implementation of peer tutoring learning models to improve the ability to read Al-Quran students on Al-Quran Hadith subjects in the Madrasah Ibtidaiyah Al-Hidayah Palembang The samples in this study were 60 class $V$ (five) students, consisting of two classes, namely the VA class as the experimental class and the VB class which became the control class. From the results of the implementation of the research it can be seen that the posttest results of the experimental class students using the complete peer tutoring learning model increased the initial percentage from $13 \%$ to $83 \%$, while the students classified as unfinished decreased in percentage from $87 \%$ to $17 \%$. The class average has also increased from pretest by $66.067 \%$ to $82.2 \%$. Then the ability to read Al-Quran students after the implementation of peer tutoring learning models in improving the ability to read Al-Quran students have achieved significant results because the value of to obtained by 7 this means to be greater than tt good at the 5\% level of 2.00 and good at $1 \%$ level of 2.65, the null hypothesis proposed is rejected, this means that there is a significant difference between the control class and the experimental class that has shown a significant value. So the peer tutoring learning model can be said as one of the effective learning models to improve the ability to read Al-Quran students on the Al-Quran Hadith subjects in the madrasas ibtidaiyah Al-Hidayah Palembang.
\end{abstract}

Keywords : Peer Tutor, Ability to Read Al-Qur'an.

\section{INFORMASI ARTIKEL}

Submitted, February 05, 2019

Revised, April 01, 2019

Accepted, June 07, 2019 


\section{PENDAHULUAN}

Manusia adalah makhluk sosial dan berbudaya, dimana seluruh aspek kehidupannya merupakan pembelajaran agar individu tersebut mampu hidup ditengah-tengah masyarakat. Berdasarkan hal tersebut tentunya seorang individu sangat memerlukan pendidikan dalam menjalani kehidupan bermasyarakat. Melalui pendidikan, manusia dapat belajar menjadi lebih baik (Masrianto, 2017). Pendidikan dari segi etimologis adalah sebagai kesatuan pelayanan anak didik (Sapsuha, 2013). Dengan pendidikan membawa seseorang kearah yang fositif dan memberikan dampak bagi kehidupan selanjutnya. Dalam penelitian ini akan menggunakan model pembelajaran tutor sebaya untuk melihat kemampuan membaca Al-Quran siswa. Peran guru dalam model pembelajaran tutor sebaya pada umumnya sama yaitu sebagai fasilitator, mediator, dan evaluator (Falah, 2014). Model pembelajaran tutor sebaya dipilih karena diyakini bahasa teman sebaya lebih mudah dipahami selain itu dengan teman sebaya tidak ada rasa enggan, rendah diri, malu sehingga diharapkan siswa yang kurang paham tidak segan untuk mengungkapkan kesulitan-kesulitan yang dihadapinya (Nurkhim, 2013). Anak usia sekolah dasar mempunyai semangat untuk belajar yang tinggi dibandingkan saat anak berada pada usia menengah ataupun atas. Hal ini terlihat antusias siswa dalam belajar seperti halnya dalam meniru (social imitation). Masa social imitation terjadi sekitar umur 6-9 tahun sehingga di perlukan figur yang dapat memberi contoh dan teladan yang baik dari orang-orang sekitarnya. Anak sangat cepat meniru apa yang diucapkan. Oleh karena itu pada masa sekolah dasar anak harus banyak mendapatkan motivasi dan dukungan dalam belajar sehingga mereka terpacu untuk belajar lebih giat lagi. pola perilaku anak yang khas yang tercermin pada respon yang diberikannya terhadap berbagai masalah atau situasi-situasi yang dihadapinya (Ibda, 2015). Sehingga anak mempunyai keunikan tersendiri yang harus dipahami seorang pendidik.

Dalam penelitian ini Madrasah Ibtidaiyah yang berada di kota Palembang yaitu Madrasah Ibtidaiyah Al-Hidayah Palembang yang terletak di Jalan H. Gubah Bastari Kecamatan Jakabaring Palembang. Al-Quran Hadits merupakan salah satu mata pelajaran yang harus dipelajari siswa dari kelas 1 sampai kelas 6 dari 13 mata pelajaran. Mata pelajaran Al-Quran Hadits adalah bagian dari mata pelajaran pendidikan Agama Islam pada Madrasah Ibtidaiyah yang dimaksudkan untuk memberikan motivasi, bimbingan, pemahaman, kemampuan, dan penghayatan, terhadap isi yang terkandung dalam Al-Quran dan Hadits sehingga dapat diwujudkan dalam perilaku sehari-hari sebagai manifestasi iman dan taqwa kepada Allah (Lutfi, 2012). Membaca dan memahami Al-Quran melalui mata pelajaran Al-Quran Hadits adalah wajib. Proses untuk mengenal dan memahami Al-Quran tidak pernah mengenal kata terlambat, umat Islam harus terus mempelajarinya. Oleh karena itu berbagai model dan metode pembelajaran yang diciptakan untuk meningkatkan kemampuan membaca Al-Quran. Membaca Al-Quran merupakan salah satu tujuan utama yang dilaksanakan setiap sekolah terutama sekolah yang bernaung dibawah Departemen Pendidikan Agama. Berbagai model dan metode pembelajaran yanga ditawarkan seperti metode tunjuk silang, metode iqro' dan masih banyak lagi model dan metode pembelajaran yang diterapkan agar siswa mampu membaca Al-Quran. Dalam kenyataannya terkadang siswa memiliki waktu singkat untuk membaca Al-Quran dari seorang guru yang dilaksanakan di kelas karena keterbatasan waktu yang disediakan oleh kurikulum sehingga hasil pembelajaran yang didapat pun kurang maksimal. Kegiatan pembelajaran yang seharusnya menarik, penuh aktifitas, kreatifitas dan ide-ide cemerlang, ternyata tidak berlangsung sesuai harapan, sehingga proses belajar mengajar di kelas hanyalah proses belajar mengajar yang pasif (Masrianto, 2017). Sehingga proses pembelajaran tergolong berpusat guru (teacher center). Kadangkala siswa malu untuk bertanya kepada guru apalagi jika bertanya dihadapan semua teman di kelas.

Hal ini didapat dari penuturan guru mata pelajaran Al-Quran Hadits yaitu Pak Hermansyah, S.Pd.I. Menurut beliau anak baru bisa membaca Al-Quran jika sudah dituliskan 
latinnya (bahasa Indonesia). Hal ini menjadi salah satu permasalahan tersendiri bagi guru mata pelajaran Al-Quran Hadits karena jika hal tersebut dilakukan secara terus-menerus, siswa akan terbiasa tidak mau berusaha membaca huruf Al-Quran dan hanya mengerti pada tulisan latin. Hal ini bisa terlihat dari hasil nilai ulangan harian dari seluruh kelas 4,5 dan 6 yang berjumlah 186 orang siswa didapat hanya sekitar 50 orang yang mampu membaca Al-Quran.

Setelah Peneliti melakukan penelitian awal terlihat bahwa siswa hanya berpusat pada guru (teacher center) sehingga siswa terlihat pasif dalam proses belajar dan mendengarkan ceramah dari guru di depan kelas. Kemudian untuk meniru bacaan dalam bahasa arab dengan mudah mereka melakukannya. Sedangkan untuk membaca huruf arab tanpa latin mulai mengalami kendala. Hal ini bisa terlihat saat dilakukan evaluasi diakhir pelajaran ataupun ulangan harian. Terlihat dari hasil belajar siswa melalui soal-soal yang mempunyai tulisan bahasa arab mereka mulai kebingungan untuk mengisi lembar jawaban tersebut. hal ini yang menjadi latarbelakang peneliti untuk melakukan penelitian khususnya untuk Madrasah Ibtidaiyah Al-Hidayah Palembang yang sebagian besar mata pelajaran terdapat ayat Al-Quran yang wajib dipelajari. Madrasah Ibtidaiyah adalah satuan pendidikan formal yang menyelenggarakan pendidikan umum dengan kekhasan agama Islam. Tetapi dalam kenyataannya sebagai salah satu Madrasah Ibtidaiyah swasta yang berada di kota Palembang menyatakan sebaliknya. Sebagian siswa masih banyak yang belum bisa membaca Al-Quran dengan baik dan benar seperti pengenalan huruf hijaiyah yang masih belum sempurna, bacaan mad, dan pengenalan syakal sehingga ketika mereka membaca Al-Quran atau pun Hadits, hanya melihat huruf latinnya saja.

\section{METODOLOGI PENELITIAN}

Jenis penelitian yang digunakan adalah penelitian lapangan (field research), yaitu penelitian yang bertujuan untuk mengetahui pengaruh atau sebab akibat dengan cara membandingkan hasil kelompok eksperimen dan kontrol. Penelitian ini menggunakan pendekatan penelitian kuantitatif yang mana penelitian ini menganalisis menggunakan bilangan agar mengandung makna yang lebih tepat dari pada menggunakan kata-kata. Pendekatan penelitian kuantitatif didasari oleh filsafat positivisme yang menekankan fenomena-fenomena objektif dan dikaji secara kuantitatif (Sukmadinata: 2013). Menurut Sugiyono pendekatan penelitian kuantitatif yang digunakan dalam meneliti pada populasi atau sampel tertentu, teknik pengambilan sampel pada umumnya dilakukan secara random. Desain dalam penelitian ini adalah eksperimen kuasi atau sering disebut juga eksperimen semu dengan jenis Nonequivalent Control Group Desaign artinya desain pretest dan posttest yang tidak ekuivalen (Emzir: 2014). Pada dasarnya kuasi eksperimen sama dengan eksperimen murni tetapi bedanya dalam pengontrolan variabel. Desain kuasi eksperimen hanya salah satu variabelnya dilonggarkan.

Subjek dalam penelitian ini adalah siswa kelas V yang terdiri dari kelas VA dan VB yang seluruhnya berjumlah 60 siswa. Terdiri dari kelas eksperimen yaitu kelas yang akan mendapat perlakuan untuk melaksanakan model pembelajaran tutor sebaya sebanyak 30 siswa sedangkan kelas kontrol adalah kelas yang tidak menggunakan model pembelajaran tutor sebaya dalam proses pembelajaran tetapi masih menggunakan model pembelajaran konvensional seperti ceramah, tanya jawab, pengulangan dan setoran hafalan.

\section{HASIL DAN PEMBAHASAN}

Sebelum melaksanakan tes setiap siswa melakukan pretest baik kelas kontrol maupun kelas eksperimen untuk melihat kemampuan awal siswa sekaligus menentukan yang akan dijadikan tutor yang berada di kelas eksperimen. Setelah ditentukan yang menjadi tutor kemudian dilaksanakan model pembelajaran tutor sebaya pada kelas eksperimen sebanyak enam kali pertemuan dengan setiap pertemuan dilaksanakan pretes diawal pertemuan dan 
melaksanakan posttes diakhir pertemuan. Langkah-langkah dalam pelaksanaan model pembelajaran tutor sebaya yaitu : 1) Siswa dibagi kelompok dalam hal ini satu kelompok terdiri dari 2 atau 3 siswa yaitu satu sebagai tutor dan lainnya yang akan mendapat bimbingan, 2) Kemudian siswa mendengarkan penjelasan guru tentang apa yang akan menjadi tugas kelompok, 3) Siswa melaksanakan tugas dengan dibatasi waktu yang telah ditentukan, 4) Selama siswa yang bertindak sebagai tutor membimbing siswa yang mendapat bimbingan guru mengawasi jalannya pelaksanaan model pembelajaran tutor sebaya tersebut, 5) Setelah waktu yang telah ditentukan berakhir maka giliran guru untuk melihat kemampuan membaca AlQuran siswa dari hasil bimbingan tutor apakah telah mengalami kemajuan.

Kemudian untuk kelas kontrol dilaksanakan juga pelaksanaan penelitian tetapi yang berbeda pada penggunaan model pembelajaran. Kelas kontrol masih menggunakan model pembelajaran yang konvensional yaitu model pembelajaran yang biasa guru mata pelajaran AlQuran Hadits gunakan seperti diawali dengan ceramah, tanya jawab, pengulangan dan terakhir setoran hafalan. Setelah dilaksanakan penelitian pada mata pelajaran kelas Al-Quran Hadist pada kelas eksperimen menggunakan model pembelajaran diperoleh data sebagai berikut : kemampuan membaca Al-Quran siswa setelah diterapkannya model pembelajaran tutor sebaya dalam meningkatkan kemampuan membaca Al-Quran siswa telah mencapai hasil yang signifikan karena nilai $t_{0}$ diperoleh sebesar 7 ini berarti $t_{0}$ lebih besar dibandingkan $t_{t}$ baik pada taraf 5\% sebesar 2,00 dan baik pada taraf 1\% sebesar 2,65 maka hipotesis nihil yang diajukan ditolak, ini berarti bahwa adanya perbedaan signifikan antara kelas kontrol dan kelas eksperimen yang telah menunjukkan nilai yang signifikan. Dari hasil pelaksanaan penelitian tes unjuk kerja kemampuan membaca Al-Quran siswa pada mata pelajaran Al-Quran Hadits materi membaca surat Al-Alaq terlihat hasil posttest siswa kelas VA yang menjadi kelas eksperimen dengan menggunakan model pembelajaran tutor sebaya yang tergolong tuntas meningkat persentase awal sebelum menggunakan model pembelajaran tutor sebaya sebanyak $13 \%$ menjadi 83\% setelah menggunakan model pembelajaran tutor sebaya. ini berarti pada kelas eksperimen yang menggunakan model pembelajaran tutor sebaya meningkat cukup signifikan. Sedangkan siswa yang tergolong belum tuntas menurun persentasenya dari 87\% sebelum menggunakan model pembelajaran tutor sebaya berubah persentasenya menjadi $17 \%$ siswa yang belum tuntas. Rata-rata kelas juga sudah meningkat dari pretest sebesar 66,067 \% menjadi 82,2 \% pada posttest. Jadi model pembelajaran tutor sebaya dapat dikatakan sebagai salah satu model pembelajaran yang efektif untuk meningkatkan kemampuan membaca Al-Quran siswa pada mata pelajaran Al-Quran Hadits di madrasah ibtidaiyah Al-Hidayah Palembang.

Selain dari data penelitian statistik, hasil penelitian ini juga diperkuat dengan keadaan di sekolah Madrasah Ibtidaiyah Al-Hidayah Palembang. Selama ini pernah dilakukan pembelajaran yang menggunakan model pembelajaran aktif tetapi tidak untuk mata pelajaran pendidikan agama Islam khususnya mata pelajaran Al-Quran hadist. Selama penelitian berlangsung peneliti mengamati siswa dalam mengikuti proses pembelajaran. Para siswa sangat antusias dalam mengikuti model pembelajaran tutor sebaya, dalam hal ini teman sebaya yang membimbing teman sekelasnya yang perlu mendapat bimbingan. Selama proses pelaksanaan model pembelajaran tutor sebaya terlihat siswa merasa tidak ada beban ataupun segan jika belajar dengan sesama temannya. Di kelas eksperimen terjadi proses pembelajaran yang efektif dan interaksi yang terjadi antara tutor dan yang dibimbing sangat terjalin sangat baik walaupun di ikuti dengan canda tawa sesama siswa. Hal ini diperkuat dengan hasil wawancara siswa kelas eksperimen tentang tanggapan mereka mengenai model pembelajaran tutor sebaya. Resepon mereka sangat fositif. Mereka senang bisa belajar bersama temannya yang bertindak sebagai tutor sehingga tidak merasa ada beban jika dibandingkan belajar dengan guru mata pelajaran.Tetapi hal ini tidak menyurutkan siswa untuk terus melakukan proses pembelajaran tutor sebaya yang kadangkala tutor mengalami kendala dalam mengajari teman 
sebayanya yang dibimbing, tetapi langsung ditanyakan kepada peneliti untuk memperbaiki bacaan yang salah agar bisa dibacakan kembali kepada siswa yang mendapat bimbingan.

Jelas bahwa dalam proses pelaksanaan pembelajaran aktif dibutuhkan sesuatu yang bervariasi untuk menunjang semangat dan keaktifan siswa dalam belajar. Selain itu karakteristik siswa yang mempunyai keunikan masing-masing juga perlu diperhatikan untuk menunjang dalam proses pembelajaran yang efektif. Seperti salah satunya dengan mengajak siswa belajar mata pelajaran Al-Quran di luar kelas atau pun di ruangan terbuka yang berkaitan dengan materi pelajaran. Juga tidak kalah pentingnya peran guru sebagai peletak dasar kegiatan pembelajaran apakah tujuan yang diharapkan tercapai atau hanya akan menjadi sebagai salah satu tuntutan untuk menuntaskan materi pelajaran. Guru yang aktif dan kreatif dapat mencari dan memvariasikan model atau metode pembelajaran yang disesuaikan dengan materi pelajaran yang sesuai dengan karakteristik siswa. Dalam mata pelajaran pendidikan agama Islam khususnya mata pelajaran Al-Quran Hadits yang identik dengan metode hafalan sulit untuk memvariasikan model atau metode pembelajaran yang akan digunakan. Padahal untuk mengahafal ayat Al-Quran diperlukan suatu pemahaman dalam membaca dan efisiensi waktu yang cukup lama. Nabi Muhammad saw pertama kali menerima wahyu dari Allah swt melalui perantara malaikat Jibril mendapat perintah untuk membaca surat Al-Alaq ayat 1-5. Jadi hal yang pertama kali diajarkan kepada anak adalah cara membaca ayat Al-Quran kemudian baru menghafalnya. Oleh karena itu model pembelajaran tutor sebaya dijadikan sebagai salah satu model pembelajaran alternatif untuk meningkatkan kemampuan membaca Al-Quran siswa. Terbukti model pembelajaran tutor sebaya menjadi salah satu model pembelajaran yang mampu untuk meningkatkan kemampuan membaca Al-Quran siswa. Walaupun model pembelajaran tutor sebaya tidak terlepas dari metode pembelajaran lain yang mendukung proses pelaksanaan model pembelajaran tutor sebaya seperti metode hapalan, dan pengulangan (drill). Setelah membaca berulang-ulang yang diajarkan tutornya, siswa yang mendapat bimbingan mulai secara perlahan mampu membaca surat Al-Alaq. Selain itu hasil yang di dapat dari model pembelajaran tutor sebaya, siswa yang menjadi tutor lebih dapat meningkatkan kemampuan membaca Al-Qurannya karena selama menjadi tutor, siswa tersebut selalu belajar dan meningkatkan kemampuan membaca Al-Quran dan jika ada ayat Al-Quran yang kurang dipahami langsung bertanya pada guru ataupun peneliti. Kemudian siswa yang mendapat bimbingan memperoleh pengalaman dengan melihat temannya sebagai tutor berupaya untuk membantunya dalam belajar. Setelah dilakukan wawancara dengan siswa kelas eksperimen tentang tanggapan mereka mengenai model pembelajaran tutor sebaya resepon mereka sangat fositif. Mereka senang bisa belajar bersama temannya yang bertindak sebagai tutor sehingga tidak merasa ada beban jika dibandingkan belajar dengan guru mata pelajaran. Selain itu interaksi yang terjadi antar siswa terjalin dengan komunikatif menjadikan model pembelajaran tutor sebaya mudah untuk dilaksanakan. Dalam suatu proses pelaksanaan pembelajaran diperlukan kerjasama antar siswa dan guru untuk sama-sama mencapai tujuan pembelajaran yang diharapkan yaitu mampu membaca Al-Quran dengan baik dan benar.

\section{KESIMPULAN}

Dalam proses pelaksanaan pembelajaran, pendidik harus mampu mengetahui situasi dan kondisi kelas yang akan berlangsungnya proses pembelajaran. Berbagai komponen yang perlu dipersiapkan pendidik sebelum menghadapi peserta didik. Salah satunya dengan menentukan model pembelajaran yang cocok untuk peserta didik dengan mempertimbangkan situasi dan kondisi kelas. Model pembelajaran tutor sebaya terbukti efektif menjadi salah satu model pembelajaran yang digunakan dalam pelaksanaan penelitian dengan judul efektivitas model pembelajaran tutor sebaya untuk meningkatkan kemampuan membaca Al-Quran siswa pada mata pelajaran Al-Quran hadits di madrasah Ibtidaiyah Palembang. Dalam penelitian ini yang 
menjadi objek penelitian adalah siswa madrasah ibtidaiyah Al-Hidayah Palembang kelas V yang terdiri dari kelas VA sebagai eksperimen dan kelas VB sebagai kelas kontrol. Kemampuan membaca siswa meningkat setelah menggunakan model pembelajaran tutor sebaya. Model pembelajaran tutor sebaya adalah salah satu model pembelajaran aktif dengan melibatkan siswa yang memiliki kemampuan lebih untuk membimbing teman sebayanya atau teman kelasnya yang masih kurang memiliki kemampuan belajar yang selama ini hanya belajar dari guru mata pelajaran. siswa bisa belajar dengan teman sebaya atau teman sekelasnya dengan harapan mampu meningkatkan kemampuan membaca Al-Quran. Setelah dilaksanakannya pelaksanaan model pembelajaran tutor sebaya siswa merasa senang dan antusias belajar bersama teman sebayanya sehingga tidak segan untuk bertanya dan mengulangi materi yang belum di pahami. Selain itu model pembelajaran tutor sebaya dapat meningkatkan kedekatan emosional antar sesama siswa dibandingkan belajar dengan guru mata pelajaran. sehingga Dengan adanya model pembelajaran tutor sebaya diharapkan mampu menjadi referensi guru melaksanakan pembelajaran di kelas.

\section{DAFTAR PUSTAKA}

Emzir. (2014). Metodologi Pendidikan Kualitatif dan Kuantitatif. Jakarta: Raja Grafindo Persada.

Sukmadinata , S, N. (2013). Metode Penelitian Pendidikan. Jakarta: PT Remaja Rosdakarya.

Masrianto, A, dkk. (2017). Efektivitas Penggunaan Model Pembelajaran Tutor Sebaya untuk Meningkatkan Minat Belajar Siswa. Pesagi. Jurnal Pendidikan dan Penelitian Sejarah, 5(8), 1-12.

Lutfi, A. (2012). Pembelajaran Al-Quran dan Hadits. Jakarta: Dirjen Pendis Kemenag.

Ibda, F. (2015). Perkembangan Kognitif: Teori Jean Piaget. Aceh: Intelektualita.

Nurkhim, A. (2013). Efektivitas Pembelajaran Tutor Sebaya dalam Pembelajaran Akutansi Biaya 1. Jurnal Pendidikan Ekonomi Dinamika Pendidikan, 8(1), 26-37.

Sapsuha, T. (2013). Pendidikan Pascakonflik. Yogyakarta: Printing Cemerlang.

Falah, I, F. (2014). Model Pembelajaran Tutorial Sebaya Telaah Teoritik. Ta'lim : Jurnal Pendidikan Agama Islam, 12(2), 175-186. 